\title{
Old Literacies and the "New" Literacy Studies: Revisiting Reading and Writing
}

\author{
Norm Friesen Ph.D. \\ Visiting Professor, Media \& Technology Studies \\ University of British Columbia \\ Faculty of Education \\ Curriculum \& Pedagogy 2125 Main Mall \\ Vancouver, BC Canada V6T 174 \\ E-mail: norman.friesen@ubc.ca
}

\begin{abstract}
As media coverage of standardized test results shows, student reading, writing and math scores are a matter of keen national and international concern. It is therefore astonishing that dominant theories of "literacies" do not systematically differentiate between these "tested" abilities and much more vernacular forms. This paper addresses this gulf between theory and practice beginning with a brief précis of the now-dominant "new" or "multimodal" literacy studies, and of the development of these approaches from work in comparative cultural anthropology. It then highlights findings from recent archeological research that suggests quite different conclusions about the development and reproduction of sophisticated inscriptive and interpretive practices in human societies. The paper concludes by considering the broad implications of these findings, and of the concomitant normative investment of education to established textual forms and standards.
\end{abstract}

Keywords: literacy, multiliteracies, writing, ethnography

\section{New and Multi-Literacies}

Twenty years ago, in 1994, a group of ten literacy researchers and theorists from Australia, the US and UK met in New London, New Hampshire. They were motivated by the shared conviction that "what students needed to learn was changing... [and] that there was not a singular, canonical English that could or should be taught anymore" (New London Group, 1996, p. 63). In the resulting "statement of general principle," these participants outlined an ambitious program to develop pedagogies of situated and transformed literacy practice and to fashion a common "metalanguage of multiliteracies" (1996, p. 73). This metalanguage would be used for "talking about language, images, texts, and meaning-making interactions," whatever the modality and medium (1996, p. 77). Although the intervening two decades have resulted in divergent work, the participants have stood by the group's founding principles and on this basis have undertaken (and also inspired) a vast array of studies.

In an introduction to the "New Literacy Studies" (2007), one of the most prolific participants of the New London Group, J ames Paul Gee, leaves little doubt as to the situated and relative nature of linguistic and literary practices: "There really is no such thing as language' in general, no such thing even as 'English' in general. Rather, people adopt different ways with oral... and printed ...words 
within different and specific sociocultural practices" (2002, p. 31). In the place of overburdened terms like "language" or "English," Gee advocates the use of capital-D “Discourse:”

\begin{abstract}
A Discourse integrates ways of talking, listening, writing, reading, acting, interacting, believing, valuing, and feeling (and using various objects, symbols, images, tools and technologies) in the service of enacting meaningful socially situated identities and activities. Being-doing a certain sort of physicist, gang members [sic], feminist, first-grade child in Ms. Smith's room... a regular at the local bar, are all Discourses. (2003, p. 35)
\end{abstract}

Discourse, according to Gee, is present in any and every human situation; and one instance is effectively the same quality as another. New London member Gunther Kress reaches a similar conclusion while using a more abstract, semiotic vocabulary: "Generalizing, I wish to say that signs are always motivated... by the producer's 'interest'... and [are thus] never arbitrary" (1992, pp. 173, 180). The meaning of a sign, word or sentence, Kress is saying, is not so much determined by arbitrary convention as it is simply by what its author intends it to be. Kress goes on to explain that this puts "us" as readers at a significant disadvantage: "our possibilities of attending to potential discrepancies in interest are severely curtailed, by the multitudinous pressures which surround every act of communication and which curtail attempts at a critical reading" (1992, p. 178). Readers are left to guess at the producer's or author's actual interest or motivation, and are consequently not positioned to judge one "motivated" expression superior or inferior to another. It follows that a gang member's graffiti is as important to the New Literacy Studies as a physicist's grammaticality; student's work with prime numbers as vital as with Pokémon powers. All are Discourses, manifestations of literacy, socially contingent forms of "meaning making."

These uncompromisingly relativist positions contrast sharply with what remains an everyday reality in school literacy curricula and instruction. In these contexts, meaning is not seen as primarily relative and subjective, and the existence and value of correct English is not in dispute. Taking this gulf between theory and practice as its principle concern, this paper first presents a critical analysis of the empirical and methodological grounding of the New Literacy Studies, and then offers its own comparative empirical case that points to rather different conclusions. It ends with a consideration of the farreaching implications of the normative commitment of formal education to established textual literacies, and the practical pedagogical differences that separate these literacies from more vernacular forms.

The emphasis of the New Literary Studies on the culturally relative nature of expression, on expressive practice in any and all of its forms, owes much to anthropology, "the study of human diversity," to which the relativity of all cultures and practices is axiomatic (Cole, Gay, Glick \& Sharp 1971, p. 4; Boas, 1940). Anthropology became influential in educational discourse (discourse without a capital "d") starting in the 1990s, when terms like "participation," "apprenticeship," and "communities of practice" started to appear and reappear in educational writing. Anthropological studies undertaken outside places typically associated with "knowledge work" (like a lab or office) generally formed the basis for this influence. These studies included influential reports and interpretations of sewing and literacy practices in Liberia (Scribner \& Cole, 1981), midwifery in the Yucatan peninsula (Lave \& Wenger, 1991), and recipe-book math in the US (Rogoff, 1991).

A key publication in this anthropological or ethnographic turn is the 1989 "Situated Cognition and the Culture of Learning" by Seely-Brown, Collins and Duguid. It begins by pointing out that recent "ethnographic studies of learning and everyday activity ... reveal how different schooling is from the activities and culture that give meaning and purpose to what students learn elsewhere" (p. 
35). With only a few exceptions (e.g., Wenger 1998, also mentioned below) these studies develop broad conclusions about contemporary education using examples from outside of the modern professional settings of the laboratory, office, meeting room and certainly the lecture hall, study group or seminar. What these studies emphasize is that mathematics, reading and writing, and many other more obviously practical skills (e.g. sewing, meat cutting, cooking) acquire their meaning only within a very specific situation (at the sewing machine, the butcher's block or the kitchen stove) - and that "learning and cognition" more generally "are fundamentally situated." In these situated, immersive contexts, a type of spoken language dominates that Seely-Brown, Collins and Duguid characterize as "indexical:"

\begin{abstract}
Indexical terms are those that "index" or more plainly point to a part of the situation in which communication is being conducted. They are not merely context-sensitive; they are completely context-dependent. Words like I or now for instance, can only be interpreted in the context of their use [and are indexical]. Surprisingly, all words can be seen as at least partially indexical. (pp. 32-33)
\end{abstract}

Indexical language is localized in activity, in engagement with the environment as it is immediately present. This language is embedded situationally in the literal sense of indexical physicality. This indexing or contextual referencing of the world, the three authors claim, is no less than the basis for learning and knowledge in general: "Knowledge, we suggest, indexes the situation in which it arises and is used" (p. 36). As a result, learning becomes a process of enculturation, which has also been called "legitimate peripheral participation." Tasks take the form of practical or "cognitive apprenticeships," arrangements through which someone less experienced is "shown the ropes," almost literally, through talking, pointing and other situated action. A learner is gradually inducted, through indexical language, demonstration and participation, into a particular practice and the community of practice constituting it. ${ }^{i}$

\title{
2. Experimental Anthropology: A Study of "Restricted Literacies"
}

One anthropological study in particular that is "widely cited in support of New Literacy Studies" (Stephens, 2000, p. 13), and that serves as "a major reference" in literacy research more generally (Botha, 2004, p. 38), is Scribner and Cole's The Psychology of Literacy (1981a). Because of the breadth and depth of its impact, this text is discussed here at some length. Scribner and Cole investigate the relationship between multiple literacies and cognitive abilities among the Vai tribe of Liberia. Their case was at once unique and representative: The literacies of tribal members were in English, Arabic and Vai, and literacy in each language was highly differentiated in both its origins and functions - although all three literacies were confined almost entirely to a small male minority (1981b, p. 62). First, reflecting British colonial history, a small fragment of these males were taught to both read and write in English for administrative work, "in Western-type government and mission schools" (Scribner \& Cole 1981b, p. 69; see also: Scribner 1984). Second, a larger number (including a few females) learned as children not to write, but to read and recite Arabic from the Koran. Vai script, finally, was learned in informal circumstances, and was used largely for personal and financial record keeping and communication.

Scribner and Cole characterize their research study as an "experimental" "comparative anthropology," as research which identifies the cognitive effects of literacy. It compared the specific conditions of the acquisition and use of each of these literacies, paying particular attention to teaching and learning of Vai script, a literacy that they regarded as "indigeneous," and as as originating 
independently among the Vai. Through their comparative analysis, Cole and Scribner discovered that literacies different in origin and function bring with them different cognitive characteristics:

All our information points towards the specificity of literacy [and associated skills]... Literacy is not simply knowing how to read and write a particular script, but applying this knowledge for specific purposes in specific contexts of use. (1981a, p. 236)

Literacy, in other words, is neither absolute nor monolithic; it is culturally constructed and contextually situated - embedded like cognition itself in particularized activity. The specific skills and applications involved, moreover, are not generalizable across contexts and cultures, but are particularized within these.

Although these simple but powerful conclusions are widely referenced and reiterated, Scribner and Cole's revealing descriptions of the very restricted use of these literacies are only infrequently noted. All three forms of literacy, English, Arabic and Vai, are marked by a fundamental superfluity, to use Scribner and Cole's own term. The "basic productive activities and the workings of the social order," the authors observe, "do not seem to depend in any critical way on writing" of any kind. In addition, no one literacy is associated with "learning of new knowledge nor involve[s] individuals in new methods of inquiry" (Scribner \& Cole 1981b, p. 66). Characterizing Vai script in particular as a case of "restricted literacy" (1981a, p. 239), the authors note the absence of any publically-available texts or religious canon in the Vai language, and of any standardized orthography for the characters of the Vai syllabary. ii They also observe that Vai is nowhere used to record "persuasive arguments," "personal experiences" or "poetic" expression (1981b, 65). Finally, Scribner and Cole were unable to identify any "educational activity that [was] mediated by standardized written materials in Vai" (1981a, p. 238).

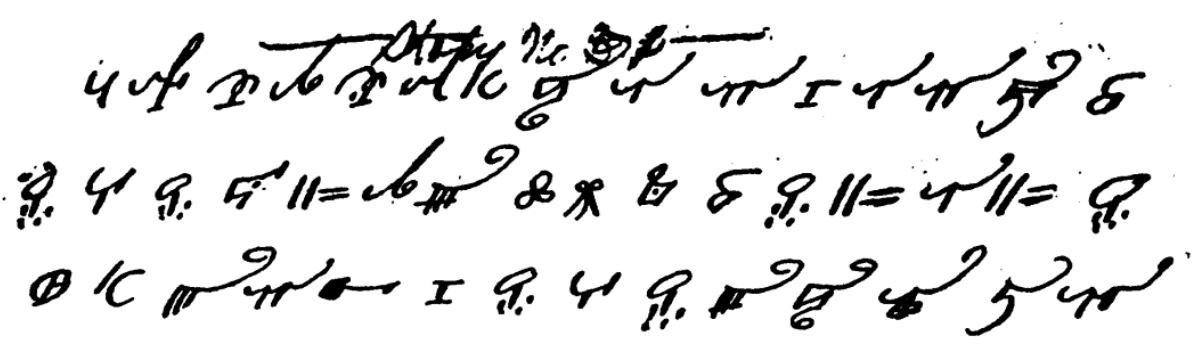

Figure 1: Fragment of a representative "rascal man" narrative in Vai: "One man live to take a walk to go to some place. He go and catch one big town. All the people join for play." (Courtesy of Dennis J. Stallings; used with permission.)

\section{Literacy without Schooling?}

Why is a study focusing on a set of literacies so restricted and foreign to modern contexts so influential? One answer is that despite its "restricted" and "superfluous" nature, Vai literacy presents Cole and Scribner with what they see as a remarkable exception - a type of "literacy without schooling" (as they put it in the title of a 1978 article). Rather than the literacy of colonialist history (i.e., English) or of an "imported" monotheism (i.e., Arabic; see: Scribner, 1984), Vai is an indigenous, vernacular script - although it likely did not arise sui generis, as Scribner and Cole claim (e.g., see: Tuchscherer, 2002). Facility in reading and writing in Vai is also acquired in ways that themselves appear indigenous and colloquial. "Becoming literate in Vai script," in contrast to schooled literacy, "is not child's play," the authors warn; "It is generally re served for young men in their late teens and twenties" (1981a, p. 65). It occurs 
through informal and non-hierarchical arrangements, in a manner that reminiscent of a kind of apprenticeship:

\begin{abstract}
transmission of the Vai script occurred in such a way as not to transform the social relationships among individuals into a formal teacher-learner relationship. A definite accent lies on the teacher and pupil living and working together. One informant reported, for example, that he began to learn when he went to work at a sawmill... where a fellow sawyer was able to read and write Vai script. (1981a, p. 65-66) ${ }^{\text {iii }}$
\end{abstract}

Via is taught and learned, it appears, in a manner embedded in everyday life, situated in an authentic, inherently meaningful context, rather than in the artificiality of the classroom, its rules and instructions. Scribner and Cole do not go so far as to recommend, as does Gee, that English textual literacy could or should also be taught through such popular and informal "cultural processes" (2004, p. 108). However, they do ask why "institutionalized learning programs have thus far failed to tap the wide range of 'indigenous' interests and practices which confer significance on writing." They then emphasize that "ethnographic studies of writing in different communities and social contexts - in religious, political and fraternal groups might help broaden existing perspectives" (1981a, p. 69).

This conclusion or recommendation can be read as effectively anticipating and framing decades of new and multiliteracy studies that followed. The one difference from Scribner and Cole's recommendation and what has followed in New Literacy Studies is that "writing" and "religious, political and fraternal groups" is interpreted in the most figurative and generalized terms imaginable. Vernacular or quasi- "indigenous" examples for investigation now include contexts and communities associated with computer games, mobile apps, online fan fiction, and these studies invoke a panoply of "literacies" well beyond simply reading and writing.

Finally, Cole and Scribner underscore the degree to which the indigeneous "interests and practices" they studied differ from those of schooled literacy:

Our research highlights the fact that the kind of writing that goes on in school has a very special status. It generates products that meet teacher demands and academic requirements but may not fulfill any other immediate instrumental ends. Is this an unavoidable feature of writing instruction? (1981a, p. 135)

Despite the anthropological principle of cultural relativity, there is a decidedly negative caste to phrases such as "formal... teacher demands," abstract "academic requirements," schooling as "child's play," and its removal from "any... immediate instrumental ends:" Are these and other limitations of traditional textual literacy simply just "unavoidable feature[s] of writing instruction?"

\title{
4. “Non-Restricted Literacy:" A Comparative Alternative
}

Matters of relativity and negativity aside, this paper now presents its own attempt to answer Scribner and Cole's provocative question, which can be rephrased as: "Are the characteristics of formal writing instruction indeed inseparable from textual literacy?" To answer this question, this paper considers a body of evidence that translation and digitization efforts have only very recently made available for consideration. This evidence is found in the form of a literate culture that died out well before currently hegemonic Western archetypes for education and schooling emerged (starting in classical Greece). This culture or example is also quite alien from hegemonic and colonialist models 
in terms of the technology and materiality of the literary artifacts and processes involved. "Literacy and schooling," to use Cole and Scribner's terms, are not confounded in this culture because it predates by millennia the appearance of these concepts as modern social constructs. The literacies reproduced in this culture, moreover, are not as highly "restricted" as those of the Vai. They were indispensable, rather than superfluous, to full cultural, social and economic participation. In further contradistinction from Vai, the literacy instruction in this culture was clearly connected with a body of public texts - including texts serving expressive, poetic, and analytic purposes.

Christine Proust, one of the few educational researchers to study instruction in this culture, notes that it is precisely because of the simultaneous cultural importance and alien materiality of this ancient writing that we now have such a richly detailed record of it. Speaking perhaps anachronistically of "curricula" and "education," she remarks that "no other educational system of the past is as well documented" (2011, p. 162). Proust continues,

\begin{abstract}
it is mainly the production of students that has been preserved [in the form of] clay tablets written ...during the first stage of their education (or 'elementary level'). ...These tablets were discovered in many archaeological sites, over a large geographical area, including present-day Iraq, Iran, and Syria. On these tablets, young scribes wrote out exercises for learning cuneiform writing, Sumerian vocabulary and grammar, numbers, measures, and calculations. (2011, p. 162)
\end{abstract}

This material evidence comes from ancient Sumer or Mesopotamia, particularly at the south-eastern tip of the Fertile Crescent, from about 2000 BCE. ${ }^{\text {iv }}$ These tablets were inscribed with a blunt reed, calame or stylus, creating triangular or cuni (Latin for triangle) forms in the hardening clay. The writing system constructed from these forms consisted of about 500 symbols in total. Like the writing system of the Vai, most (but not all) of these symbols stood for syllables (rather than for atomistic phonemes, as is the case for phonetic alphabets). It is among the earliest (if not the first) functionally differentiated writing system in human history. This form of inscription was used largely for accounting, trade, and legal and administrative purposes, which represented specializations central to Sumerian society. It also was associated with a substantial written cultural heritage. The Code of Hammurabi, an extensive set of laws, was written and disseminated in cuneiform, as was the Epic of Gilgamesh, one of the earliest recorded poetic sagas. It is from this documentation that it is possible to understand aspects of "cuneiform culture" that flourished millennia ago. The account presented here thus differs from that of Scribner and Cole in that it does not utilize observations and descriptions of practices brought from the field, but those reported, digitized and deduced on the basis of documented material evidence.

As the name suggests, the ancient civilizations of the Fertile Crescent were based on agriculture. Cultivation, irrigation and animal husbandry were central, accompanied by a wide range of other activities, from weaving through copper-smithing to masonry. As in many other eras and societies, learning these practices or trades did not require any explicit schooling or formal education; ancient Sumer, like 20 th century Liberia, had no polytechnics or trade schools. $^{\mathrm{V}}$ As the studies of Lave \& Wenger (1991) and others (e.g., Rogoff \& Lave 1984) also confirm, what we today call "trades" were learned in ancient Sumer through apprenticeship or "on the job training;" through observation and participation, with such "workplace" learning starting at a relatively young age.

However, to learn writing, some children (mostly boys) were sequestered for years from the realm of productive labor-at considerable cost to Sumerian society. ${ }^{\mathrm{vi}}$ They were sent by their parents to a special place: A location where 
they were joined by others also learning to become scribes, and where they were overseen by one or more scribal masters. Moreover, these were places in which writing material (clay), implements for inscription and examples (collections of texts and lists) were all available in quantity. In some cases, the walls of these rooms were covered with cuneiform tablets, which were also used as building materials. In fact, these places were often known in Sumerian as edubba or "tablet houses," and students were at times called their "sons."

Here is an early description of such a tablet house, made by one of their first discoverers, archaeologist Hermann Hilprecht in 1903:

The character of the northeast wing as a combined library and school was determined immediately after an examination of the contents of the unearthed tablets and fragments. There is [such] a large number of rudely fashioned specimens inscribed in such a naive and clumsy manner with old-Babylonian characters, that it seems impossible to regard them as anything else but the first awkward attempts at writing by unskilled hands,--so-called school exercises. Those who attended a class ... [received] instruction not only in inscribing and reading cuneiform tablets, but also in shaping them properly, for not a few of the round and rectangular tablets were uninscribed. (1903, pp. 524-25)

Like Proust, Hilprecht's use of terms like "school" or education system are clearly anachronistic, indicating a presentist projection of contemporary commonplaces onto otherwise alien historical data. Despite this fact, the physicality of "the first awkward attempts at writing by unskilled hands" combined with the sheer number of surviving tablets recording these practices has led many researchers to confirm Hilprecht's initial deductions concerning instruction, reading and inscription: he had uncovered evidence of work that is part of a formalized sequence of instruction, and that is in this sense not unlike the first printing exercises of school children.

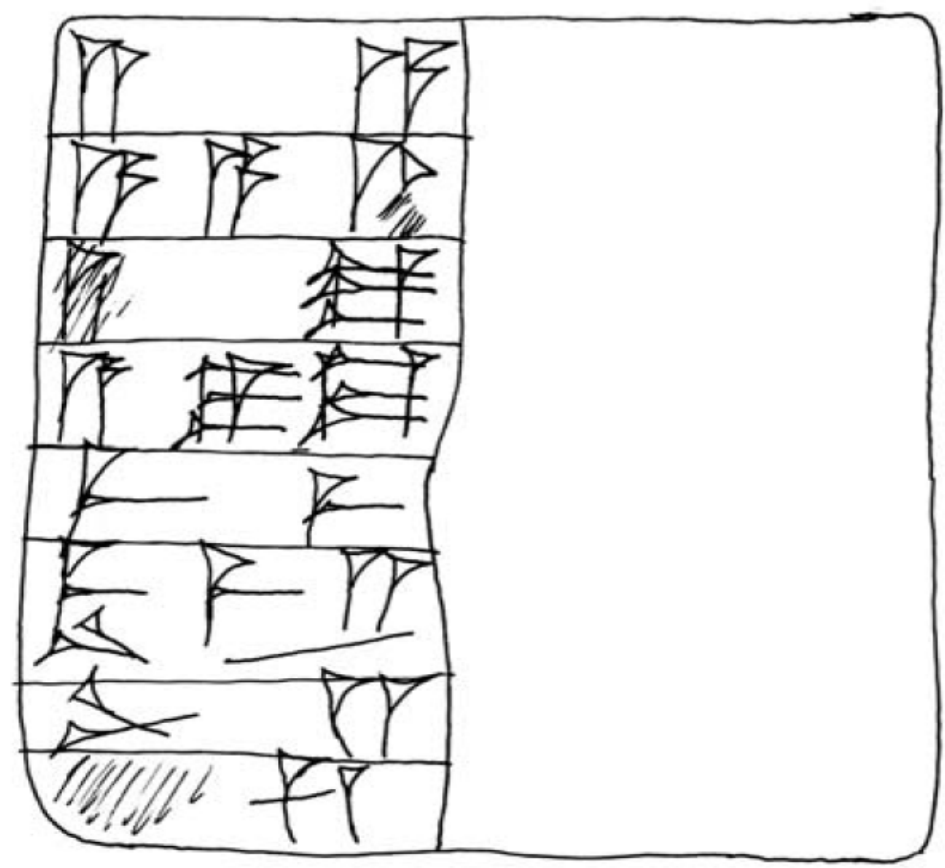

Figure 2: Teacher's model with the beginning of a traditional list of signs and sign combinations, to be copied to the right by a pupil... Large signs enable the pupil to exercise minutely every detail of the sign. (8 x 9 cm; Veldhuis 1997; used with permission) 
More extensive sequences of instruction - what we today would refer to as a "curriculum"- are also quite well documented. Speaking of what is known among archaeologists as the "Nippur Curriculum," Eleanor Robson explains:

In the first phase students concentrated on learning how to write the basic wedges that comprise cuneiform script... a vertical, horizontal, and diagonal wedge... repeated; the sign A repeated; the list of Akkadian symbols now called Syllabary A... a similar text known as Syllabary B ... [and finally,] a list of deities. (2011, p. 563)

Instructional work, as this account suggests, began with methods of refining motor skills needed for accurate, legible inscription. These physical exercises, as Robson explains, were followed by composing and copying individual and rhyming groups of syllables and words and names. In some cases, the "teacher" would render the letter forms on the tablet for the young student to copy, as illustrated in figure 2 (Veldhuis, 1997, 41-42). Among the next steps in the program of writing instruction, one which was standardized across a number of Sumerian centers (Tinney, 1998), were the inscription of words of greater complexity, including

\begin{abstract}
Short or long extracts from ...exercises ...written out on large, square, multicolumn tablets, often combined with brief passages from ad hoc and "non-canonical" lists - for instance metrology [weights and measures], personal names, place names, professional designations, lexical lists and/or literary works, proverbs, and administrative formulae... In the second phase long, single-column tablets were preferred... Students continued to copy syllabaries... plus short excerpts from incantations, hymns, literary works, and more complex lexical lists, with up to four different compositions on a single tablet. (Robson, 2011, p. 563)
\end{abstract}

One technique used to facilitate these more advanced writing exercises appears to have been recitation or dictation. The practice of pronouncing words aloud, to then have learners reproduce them in written form, has been commonplace in Western and other instructional traditions for centuries (Hoetker \&Ahlbrand 1969; Hirschler, 2013). Evidence of this in ancient Sumer takes the form of tablets that are otherwise identical except for varying spellings of homophones (Tinney, 1998, p. 49). This further implies a kind of "frontal instruction," a familiar instructional scenario in which a leader will face those facing and lead them in a common activity.

Another artifact of elementary instructional practice from ancient Mesopotamia is provided in figure 3 . It is a multiplication list or table about half the size the previous example, using the Sumerian base-60 numerical system containing an obvious error in calculation. Viewed as a scribal exercise, it illustrates a clear shift in instructional emphasis from rudimentary motor skills to much finer work, and more abstract cognitive abilities. Correspondingly, the task here is one of mathematical reasoning and a (partially mnemonic) knowledge of mathematical relations. ${ }^{\text {vii }}$ The calculations run the equivalent of $40 \times 1$ to 40 $\mathrm{x} 19$, with the one error translatable as $40 \mathrm{x} 14=550$ (Israel Museum 2012, n.p.). 


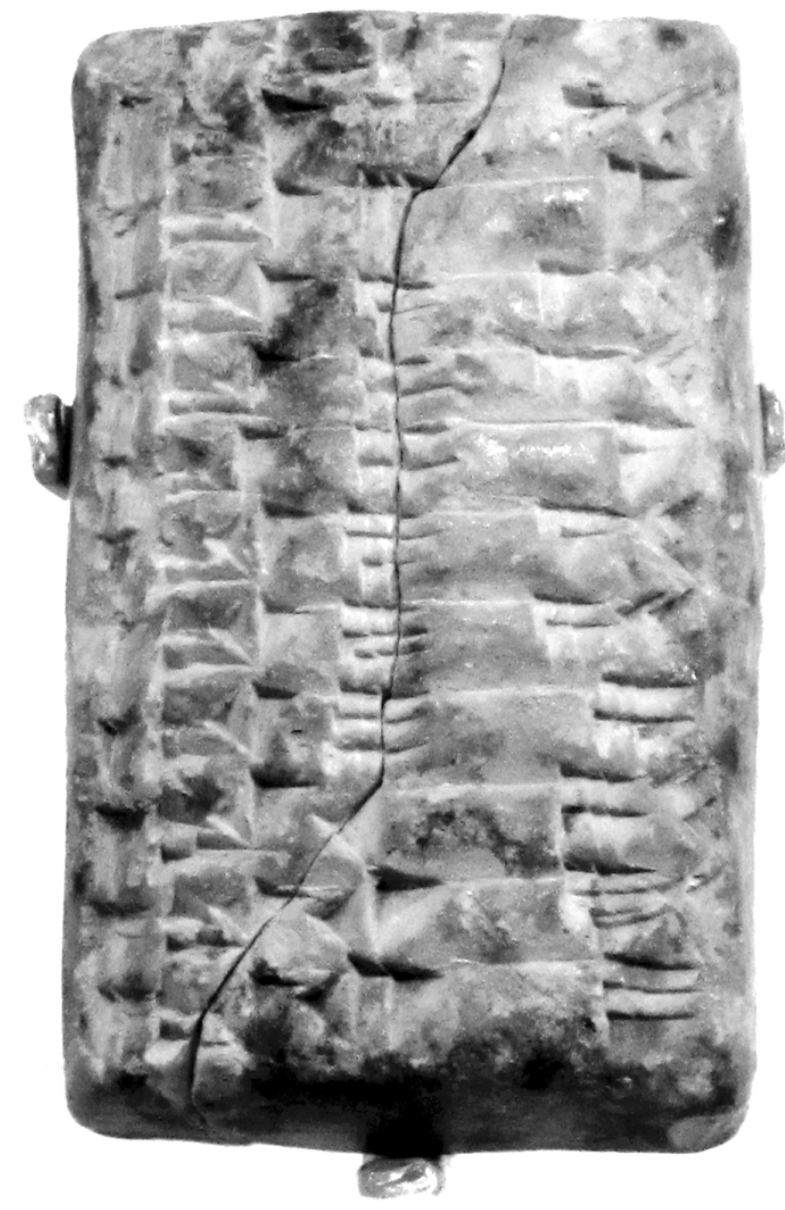

Figure 3: Multiplication Clay multiplication table inscribed with cuneiform. Babylonia (Iraq), 2nd millennium BCE. Photo by author.

Although the historical contexts for these practices could not be more different, it is impossible to ignore the remarkable similarities linking the material artifacts and practices of Sumerian instruction with modern, Western schooling in handwriting and elementary mathematics. Instruction in writing or printing in modern English-language schools (or what is called "manuscript") begins with the drawing of signs and elements, lines, circles and curved marks (one contemporary commercial product for teaching handwriting is called "Loops and Other Groups"). Teachers may begin "first of all [with uppercase] letters using straight lines (e.g., L, T, H), then letters using curved lines (e.g., C, O, U), and finally those using oblique lines (e.g., K, N, M)" (Asher, 2006, p. 466). Lower case letters soon follow, with careful attention to the types of shapes combined in these characters. Like their Sumerian forebears some 40 centuries earlier, children learning writing today are introduced to variations on individual characters, using special wide-ruled paper to develop finer motor skills. In this context, "lists of signs" and "names" have also long been important, as one classic manual on Handwriting Instruction in Elementary Schools explains:

Early [student] writing may be centered about instances as the following[:]
1. Their names
2. Telephone numbers, dates
3. Labels and captions for charts and pictures
4. Calendars
5. Records, such as temperature charts or records. 
As the children develop in handwriting skill, the teacher enlarges his role to facilitate further growth in helping pupils write their own announcements, notices to be sent home, or simple stories. (Burns, 1968, p. 21)

The one clear difference in modern day writing instruction, however, is the introduction of the student's own purposes and compositions as soon and as frequently possible in writing exercises. While Proust notes "the emergence of an ideology that legitimates the schools and the stratum of erudite scribes in the Sumerian context" (p. 161) in the culture of today's schools, students are cast neither as scribes nor copyists, but as authors of independent creations. However, from the standpoint of the pragmatics of technique and materials of instruction, the parallels between today's writing instruction and those in ancient Sumer seem more striking than the differences.

\section{Implications: Non-Restricted Literacies and Arbitrary Meanings}

The circumstances of Sumerian scribal instruction together provide a rather different example of an "indigenous" literacy than that described by Scribner and Cole. In the Sumerian example, with a relatively "non-restricted literacy" and writing systems and practices indisputably sui generis (vis a vis Western models) literacy instruction began early in life, and continued through many successive steps. In this context, what can be called "school" - an isolated and artificial environment for structured activity also isolated from immediate application- does not appear as a confounding variable. Instead, it seems to constitute a necessary precondition - one that has arisen independently in civilizations across millennia (e.g.; Mayan ca,. 300 BCE; Chinese, ca 1500 BCE)- enabling a socially indispensable, multi-functional and multidimensional set of abilities to be reproduced over generations.

It is worth considering still further implications. Already the initial motor exercises (figure 2) forcefully bring to mind Cole and Scribner's undesirable "products that meet teacher demands and academic requirements but [that] may not fulfill any other immediate instrumental ends." What justifies exercises in inscribing lines, circles, triangular forms and other letter parts is not any immediate and practical payoff, but the fact that these isolated skills are a prerequisite to more complex tasks. The acquisition of knowledge and ability in these early stages is legitimated in terms of the nature of later stages, such as the much smaller and more intricate multiplication table (figure 3). This last illustration further suggests that this "indigeneous" literacy effort imposes the highest standards for orthography and for mastery of other conventions and rules, including those of measurement and mathematics. Finally, this example of literacy is explicitly and multiply normative, from orthography (following teachers' examples) through conformity to a teacher's dictation, to accurate rendition of classical texts (an important skill when textual reproduction occurred only manually).

Further instructional characteristics become apparent, finally, by simply considering the implications of the abstract work recorded in the multiplication table (figure 3). The two sides of the tablet together represent a kind of twodimensional field in which the shape of the symbol in each position is determined not only through linear sequence, but also in relationship to those be low and above. One could go so far as to say that the symbols inscribed in the table form an intricately structured symbolic or semiotic network. Knowledge, or the values and interrelationships of each symbol, in these examples are not situated indexically, in relation to a context in the "outside world," but in relation to other symbols and values arranged on the same tablet, whose significance is rather arbitrary. 
Curriculum, dictation, alphabets, exercises, multiplication tables, instructor or teacher examples, frontal instruction, and specialized writing equipment: The material and practical analogues connecting elementary writing instruction today with the practices of ancient Sumer form quite a long list. And the ways that these relatively non-restricted "multiliteracies" (i.e., reading, writing and mathematics) were learned and taught 4000 years ago lead to a rather different set of conclusions about literacies and their acquisition foundational to new and multimodal literacy scholarship. What does such an uncanny correspondence of independent instances across millennia say about human learning, literacy and related instructional techniques?

It first, it suggests that there is an efficacy, and systematicity and mutualreinforcing interdependency of at least some of the techniques and practices associated with institutional instruction and practice. Learning how to write in the context of a relatively "non-restricted" literacy seems to require a long list of steps that have meaning only in the light of later steps. Any one set of these steps, beginning with the individual strokes of a pencil or stylus, can be readily extended and linked with further stages and skills to form a relatively long sequence or curriculum. These steps would extend from the rendition of words and phrases through multiplication tables to other highly structured forms and compositions, for example, epic poetry or astronomical data. This further suggests that writing instruction and ability is not just a matter of situated practice, of legitimate peripheral participation or of apprenticeship in ongoing and routine scribal work. The presence of what have been called curricula, of sequences of practices, with any one practice justified in terms of the next rather than in terms of immediate student gratification- further implies the existence of didactics or instruction as a specialized knowledge, particular to a single social role or function.

The parallels between ancient Sumer and modern schooling thus suggest that there may be "philosophical anthropological" reasons for many arrangements of what we call school, reasons that arise simply as a result of "the shared circumstances of being-human" (de Lara \& Taylor, 1998, p. 110). Ranging from the hierarchy of teacher and student to the linearity of curriculum, these parallels also heighten the surmise that such arrangements are necessitated by the nature of writing itself. One particularly important characteristic of writing whose implications are generally ignored or obfuscated in studies of new and multimodal literacies- is the arbitrary and self-referential nature of the writing systems and signs themselves. The opacity (to most readers) of both the cuneiform and Vai scripts in the figures provided above, for example, is the result of at least two manifest layers of arbitrary complexity: The first is the relation between the characters and the sounds they encode (since both are syllabaries). The second is the relation between combined sounds and their practical meaning (e.g., what is the sound combination for "twenty" in Sumerian or "rascal" in Vai?). Further layers include rules and conventions of counting and multiplication, as well as of social action and narrative. Of course, for those with a knowledge of ancient Sumerian or Vai languages and cultures, much or all of this opacity disappears. It goes without saying that this is reciprocal; our own writing would also appear opaque to similarly untrained eyes. Ferdinand de Saussure, the father of semiotics and modern linguistics, used the term "unmotivated" to describe this characteristic of textual symbol systems. This is the exact opposite of Gunther Kress' characterizations of the production of semiotic resources offered above. It is consequently with a related analysis of Kress' position that the concluding section of this paper begins. 


\section{Conclusion: Meaning, Arbitrariness and Educational Normativity}

Kress convincingly maintains that the words "arbitrary" and "unmotivated" do not characterize the way that meaning is experienced for a young child (e.g., Kress, 1998), whether the child is watching video, interacting with a tablet or smartphone, or involved in an imaginary game. This point is supported by the fact that what happens in these cases is not primarily symbolic in nature (although there might be symbols present). Things seen and touched in these instances either physically resemble what they stand for (e.g. an animated cartoon bear or a stuffed toy version), or they gain their meaning through a kind of correlation (the pictorial "Angry Birds" icon accesses the game). This is how these media and associated visual and interactive literacies operate (whether the user is a literate adult or a young child). Other meanings experienced by the young child, for example in imitative and imaginative play, are similarly motivated or "non-arbitrary." The convincing assertion that these kinds of self-expressions "are, literally, full of meaning," is a key part of Kress' understanding of semiosis among the very young:

With that disposition... [young children then] come to writing, which has, to the learner, all the aspects of a system of arbitrarily constructed signs. This is at odds with their own sense of what signs are and how they work... Writing initially presents itself as (and indeed is at one level) a system of signs of arbitrary construction. Given that children come to this stage as makers of motivated signs, this is incomprehensible. (1998, p. 225)

In saying that writing presents itself to the child as a system of arbitrary construction, Kress makes a key point. To learn reading and writing is to follow a veritable labyrinth through multiple layers of such arbitrary artifice. Kress continues: "The engagement with (or imposition of) literacy is not neutral or innocent... it is not, nor could it be, a domain of free experimentation for the child:"

\footnotetext{
the fact that the accretions of conventions in the system of writing over three millennia or more make it impossible to be "successful" by treating it as a system of motivated signs until the user of this semiotic system is fully within it. (Kress, 1998, p. 246)
}

Kress appears to be saying that in grappling with textual literacy, children are taking on nothing less than the accumulation of arbitrary conventions that constitute the vast legacy of a textual culture - from the sound of a given letter and its position in the alphabet to its shades of meaning it can produce different words or sentences. These conventions are accumulated in written documentation, dictionaries, grammars, advertising, literary texts, as well as in tools for writing and analysis - from the alphabet and QWERTY keyboard through multiplication and periodic tables to more ambiguous and multidimensional logical configurations and representations. The task, moreover, of inducting students into the accumulated layers of symbolic convention, of helping them become immersed in this semiotic system, is in one sense the task of schooling. As shown above, it involves work that by its very nature is abstract, academic and removed from immediate instrumentality or gratification. Only when such an immersion occurs with some degree of success do these compounded symbolic conventions, as Kress seems to suggest, become more manifestly meaningful and useful.

However this is not where Kress's reasoning (and that of others in New Literacy Studies) ends up. Instead, as indicated earlier, Kress insists that the meaning of written symbols ultimately rests with their producer or author. For Kress, and as quoted above, "signs are always motivated," by the producer's 
'interest,"' meaning that they are "never arbitrary." On this basis, and in the ellipses in the passages quoted just above, Kress is actually defending the argument that "linguists, educators, and parents" all cling to a broadly Saussurean belief that the arbitrariness of signs is a reality for both readers and writers (1998, p. 246). The widespread failure to recognize this, Kress implies, unnecessarily makes the entire enterprise of literacy more difficult and imposing for the naturally expressive child than it needs to be.

How is it that someone like Kress can seem to so effectively explain the arduous instruction and learning involved in textual literacy, yet improbably insist that it is those guiding it -linguists, educators and parents- who make it so difficult? How is it, moreover, that Kress and others in the New London Group (e.g., Cope \& Kalantzis, 2012) can generally acknowledge the arbitrary complexity of symbols, yet ignore the instructional implications that reasonably follow? An answer to these questions can perhaps be found in the ways that the methods of both semiotics and anthropology are applied by Kress, Gee and others. Kress' semiotics, in which producers' "interests" or "intentions" predominate over those of the reader, seems to derive its principles from the productions of the youngest authors and producers. (A touchstone example repeated in his work is a drawing produced and identified as a car by his 3.5 year-old son.) Looking later in a child's development would doubtlessly configure the interests of authors and readers differently. For it is a reader's or rather, a teacher's interests that are obviously in evidence in the rule-bound formulation of a multiplication table or a grammatical exercise.

A similar problem seems to arise from the ethnographic, anthropological research that underpins New Literacy Studies. Often going back to field observation of remote cultures, these methods tend to have as their unit of analysis not the significance of inscribed documents or artifacts, but the overt and observable practices and forms of participation in which such documents might be embedded or buried. From this anthropological perspective, phenomena of textual communication or "immersion in semiotic systems" is obscured if not rendered invisible. At most, textual productions appear in this research as inflexible but mysteriously important artifacts (e.g., Latour and Woolgar, 1979), or as "reifications" or lapidary codifications of otherwise living, breathing cultural enactments (e.g., Wegner, 1989, pp. 57-62). Clifford Geertz famously explains that in ethnographic thick description, artifacts like texts acquire "their meaning" only "from the role they play ... in an ongoing pattern of life, [and] not from any intrinsic relationships they bear to one another" (1973, p. 43). For many established forms of writing, however, the intrinsic relationships that textual artifacts have to one another are indispensable. Whether they take the form of page sequences, intratextual references, or forms of derivation, influence or intertextuality, such relationships are constitutive of meaning and interpretation rather than incidental or superfluous to them.

Symbolic representations, reading and writing, particularly at more advanced points in the curriculum, find their function and justification in an elevation of thinking above immediate, indexical situations. This is one meaning of the key educational phrase "knowledge transfer," and it is concretely reflected in curricula and readings standardized and generalized across space and time, whether in the global West or in ancient Sumer. Not only can a system of symbols form a semantically or logically charged set of references in itself, as illustrated in a multiplication table, but in a society dependent on literacy, action or effects across space and time (rather than those indexically situated) are the raison d'etre of writing and documentation. Indeed, when described this way, such communication sounds rather like the "metalanguage" that the New London Group hoped to develop but never delivered - one that would transform and transcend the specificity of a given situated practice. Its failure to emerge may simply be due to the fact that it was always already there - in the writing of group members and their many acolytes. 
My point in making these arguments of course is not to deny the multiplicity of modes - visual, symbolic or otherwise- that belong to all forms of semiosis, nor is it to assert the de facto legitimacy of national or international regimes of standardized testing. I also do not deny the importance of motivated expression in learning. The value of textual literacies highlighted here is also obviously not an absolute or monolithic one; it is relative to pragmatics of teaching, learning and everyday work. As Stephens notes in an earlier examination of New Literacy Studies, the point instead is as follows:

\begin{abstract}
that the written form of a standard language has a special role in education; that schooling has a special role in the induction of children into this written dialect; and also that children bring to school language capacities which must be recognised and built upon, if the induction into the standard written form of the language which is a passport to educational and economic success, and international communication, is to be successfully accomplished. (2000, p. 21; see also MacCabe, 1998)
\end{abstract}

Educational goals and purposes are profoundly different from the relativist descriptive and participatory orientations of semiotics, anthropology and ethnography, and thus from the many New Literacy studies relying on these methods. Describing and decoding a child's expressive creations is likely less politically and pragmatically challenging than inducting that child into a prescriptive textuality, for example, of International English. Kress is absolutely correct in pointing out that this or any related type of inculcation is neither an innocent nor neutral act. But there comes a point where a student's "indigeneous," vernacular practices, so helpfully illuminated and celebrated in studies in the New Literacies need to be seen outside of anthropological relativism and neutrality. A curriculum - whether in Nippur or New York-- is not a description of development, it is a prescription for it; and this is the difference that separates a relativist study of inscriptive and expressive practices from the practical realities of education. The one will be of limited value to the other until this separation is recognized and bridged.

\title{
References
}

Asher, A. (2006). "Handwriting Instruction in Elementary Schools." The American J ournal of Occupational Therapy, 60(4), 461- 471

Boas, F. (1940). Race, Language, and Culture. Chicago: University of Chicago Press.

Botha, P. (2004). Cognition, Orality-Literacy, and Approaches to First-Century Writings. In J .A.Draper (ed.) Orality, Literacy, and Colonialism in Antiquity,(pp.3763). Atlanta: Society of Biblical Literature.

Burns, C. (1968). Improving handwriting in elementary schools $2^{\text {nd }}$ Ed. Minneapolis: Burgess Publishing.

Cole, M., Gay, J., Glick, J . \& Sharp, D. (1971). The Cultural Context of Learning and Thinking: An Exploration in Experimental Anthropology. New York: Basic Books.

Cuban, L. (2011). “The Durability of Teacher Lecturing and Questioning: Historical Inertia or Creative Adaptation?" Blog posting retrieved from: http://larrycuban.wordpress.com/2011/ 06/05/the-durability-of-teacherlecturing-and-questioning-historical-inertia-or-creative-adaptation/

de Lara, P. \& Taylor, C. (1998). From philosophical anthropology to the politics of recognition: An interview with Charles Taylor. Thesis Eleven, 52(1), 103- 112.

Kalantzis, M. \& Cope, B. (2012). Literacies. Cambridge: Cambridge UP. 
Gee, J. P. (2002). A sociocultural perspective on early literacy development. In S.B.Neuman \& D.K. Dickinson (eds.) .Handbook of Early Literacy Research, Volume 1. (pp.30-42). New York: Guilford Press.

Gee, J.P. (2004). Situated Language and Learning: A Critique of Traditional Schooling. London: Routledge.

Geertz, C. (1973). “Thick Description: Toward an Interpretative Theory of Culture. In C Geertz: The Interpretation of Cultures, (pp.3-31). New York: Basic Books.

Goody, J . \& Watt, I. (1963). "The Consequences of Literacy." Comparative Studies in Society and History, 5(3), 304- 345.

Hilprecht, H. (1903). The Excavations in Assyria and Babylonia. Philadelphia: Department of Archaeology of the University of Pennsylvania.

Hirschler, K. (2013). The Written Word in the Medieval Arabic Lands: A Social and Cultural History of Reading Practices. Edinburgh: Edinburgh University Press.

Hoetker J . \& Ahlbrand, W. (1969). “The Persistence of the Recitation.” American Educational Research J ournal, 6(2), 145- 167

Israel Museum. J erusalem. Visited May, 2012.

Kress, G. (1992). "Against Arbitrariness: The Social Production of the Sign as a Foundational Issue in Critical Discourse Analysis." Discourse and Society, 4 (2), 169191.

Kress, G. (1998). “Writing and Learning to Write." In D.Olson \& N.Torrance (eds.): The Handbook of Education and Human Development, (pp.225-256). Oxford: Blackwell.

Latour, B. \& Woolgar, S. (1979). Laboratory Life: the Social Construction of Scientific Facts. Princeton: Princeton UP.

Lave, J \& \& Wenger, E. (1991). Situated Learning: Legitimate Peripheral Participation. Cambridge: Cambridge University Press

MacCabe, C. (1998). A Response to Brian Street. English in Education, 32(1), 26- 28.

Proust, C. (2012). “Master's Writings and Student's Writings: School Material in Mesopotamia. In G. Gueudet, B.Pepin \& L. Trouche (eds.) From Text to 'Lived' Resources: Mathematics Curriculum Materials and Teacher, (pp. 161-179). New York: Springer.

Robson, E. (2011). The Production and Dissemination Of Scholarly Knowledge. In K. Radner \& E.Robson (eds.) The Oxford handbook of cuneiform culture (pp. 557576). New York: Oxford University Press.

Rogoff, B. \& Lave, J . (1984). Everyday Cognition: Its Development in Social Context. Cambridge, MA: Harvard University Press.

Scribner, S. (1984). "Literacy in Three Metaphors." American J ournal of Education, 93(1): 6- 21.

Scribner, S. \& Cole, M. (1978). "Literacy without Schooling: Testing for Intellectual Effects." Harvard Educational Review, 48(4), 448- 461.

Scribner, S. \& Cole, M. (1981a). The Psychology of Literacy. Cambridge MA: Harvard University Press.

Scribner, S. \& Cole, M. (1981b). “Unpackaging Literacy.” In N.F. Whiteman (ed.) Writing. The nature, Development and Teaching of Written Communication, (pp.788). Hillsdale, NJ: Lawrence Erlbaum.

Seely Brown, J.S., Collins, A. \& Duguid, P. (1989). "Situated Cognition and the Culture of Learning." Educational Researcher, 18 (1), 33- 42. 
Stephens, K. (2000). A Critical Discussion of the "New Literacy Studies." British J ournal of Educational Studies, 48(1), 10-23

The New London Group. (1996). "A Pedagogy of Multiliteracies: Designing Social Futures." Harvard Educational Review, 66 (1): 60- 92.

Tinney, S. (1998). “Texts, Tablets, and Teaching Scribal Education in Nippur and Ur." Expedition, 40 (2), 40-50

Tuchscherer, K. \&Hair, P.E.H.(2002). "Cherokee and West Africa: Examining the Origins of the Vai Script." History in Africa, 29, 427-486.

Veldhuis, N.C. (1997). Elementary Education at Nippur. The Lists of Trees and Wooden Objects. Doctoral Thesis. Rijksuniversiteit Groningen. Available at: http:// dissertations.ub.rug.nl/ faculties/arts/ 1997/n.c.veldhuis/

Wenger, E. (1998). Communities of Practice: Learning, Meaning, and Identity. Cambridge: Cambridge University Press.

\section{Endnotes}

${ }^{i}$ In New London Group statement of general principles, "situated practice" is identified as one of four components of a recommended pedagogy. It is described as "draw[ing] on the experience of meaning-making in lifeworlds, the public realm, and workplaces" (p. 65, 1996).

ii Since 2008, the orthography of the Vai syllabary has been "standardized" as a part of the ISO Unicode Standard.

iii Of course, the nature of a writing system will significantly influence the way in which competency in its use is achieved. The Korean Hangul alphabet, for example, can be learned informally in less than a day, whereas competence in Chinese writing requires years of formal education.

${ }^{\text {iv }}$ Other, less well documented examples of schooling practices could be studied in China circa $1000 \mathrm{BCE}$, in Islam circa $800 \mathrm{CE}$, and in Israel and Babylonia in the final centuries BCE.

v Liberia's only polytechnic, "Stella Maris" in Monrovia, graduated its first class in 1999.

${ }^{v i}$ Proust (2012) explains: “We don't know how old the students were at the beginning of their scribal education. They were old enough to be able to manipulate clay and "calame" (the cane the scribes used to impress signs on wet clay), but still in the charge of their parents. Moreover, the age of the students could have changed according to the place and the period" (p. 162).

vii For a more detailed consideration of Sumerian mathematical, geometric and related "problem texts," see: Friberg, J . (2007). A Remarkable Collection of Babylonian Mathematical Texts Manuscripts in the Schøyen Collection

Cuneiform Texts I. New York: Springer. 